\title{
Representações sociais de imigração e imigrantes em jornais britânico, francês e alemão no ano 2012
}

\section{Social representations of immigration and immigrants in British, French and German newspapers at the year of 2012}

\section{Representaciones sociales de inmigración y inmigrantes en los periódicos británicos, franceses y alemanes en el año 2012}

\author{
Roberta Rangel Batista* \\ Universidade Federal do Espírito Santo - UFES, Espírito Santo, Brasil \\ Mariana Bonomo** \\ Universidade Federal do Espírito Santo - UFES, Espírito Santo, Brasil
}

\begin{abstract}
RESUMO
A imigração na Europa tornou-se um fenômeno relevante em função do grande contingente de pessoas que chega ao território todos os dias. No entanto, a relação dos imigrantes com a sociedade local pauta-se em categorias pré-existentes que concebem o outro como ameaçador e não civilizado. Tendo como referência o aporte teórico-conceitual da Teoria das Representações Sociais, o presente estudo objetivou conhecer e analisar as representações sociais de imigração e imigrante em jornais britânico, francês e alemão no ano de 2012. Para tanto, foram coletadas 127 reportagens de jornais de referência no continente, que foram tratadas pela Classificação Hierárquica Descendente do software Alceste. Os resultados demonstraram que as representações sociais de imigração e imigrante para os jornais em análise vinculam-se a themas e categorias consideradas inferiores no pensamento social. O imigrante é representado como indesejado, dinâmica que pode provocar rejeição ao diferente e manter o grupo na condição de não familiaridade.
\end{abstract}

Palavras-chave: representações sociais, imigração, Europa.

\begin{abstract}
Immigration in Europe has become an important phenomenon due to the large number of people coming into this territory every day. However, the relationship between the immigrants and the local community is based on pre-existing categories that conceive the other as a threat. Based on the theoretical and conceptual contribution of the Social Representation Theory, this study aimed to identify and analyze the social representations of immigration and immigrant at British, French and German newspapers in 2012. Therefore, 127 reports, from well-known newspapers at the continent, were collected and later analyzed by the Alceste software. The results show that the newspapers' social representations of immigration and immigrant are related to themas and categories that have a lower social position. The
\end{abstract}


immigrant is represented as unwanted, which can establish a rejection and keep the group at a non-familiarity condition.

Keywords: social representations, immigration, Europe.

\section{RESUMEN}

La inmigración en Europa se ha convertido en un fenómeno importante debido al gran número de personas que entran en el territorio. Sin embargo, la relación de los inmigrantes con la comunidad local se basa en las categorías pre-existentes para concebir al otro como una amenaza. Basado en la Teoría de las Representaciones Sociales, este estudio tuvo como objetivo identificar y analizar las representaciones sociales de la inmigración y los inmigrantes en los periódicos británicos, franceses y alemanes en 2012. Por lo tanto, se recogieron 127 informes de los periódicos de referencia en el continente que fueron tratados por el software Alceste. Los resultados muestran que las representaciones sociales de la inmigración y los inmigrantes a los periódicos están vinculadas a themas y categorías que tienen carácter menor en el pensamiento social. El inmigrante se representa como no deseado, que puede establecer un rechazo del otro y mantener al grupo con la condición de que ninguna familiaridad.

Palabras-clave: representaciones sociales, inmigración, Europa.

\section{I ntrodução}

A demarcação da diferença entre os grupos é entendida como fenômeno presente na composição dos povos e dos territórios desde os primeiros registros da história da humanidade (Brown \& Zagefka, 2011). Na história de Heródoto, por exemplo, o civilizado povo grego considerava os grupos e povos distintos a partir da ideia de oposição e conflito. Woortman (2000) afirma que, anteriormente à ocorrência de invasões bárbaras à pólis, a dominante sociedade grega criou a concepção do que seria o "selvagem" para posteriormente projetá-la sobre povos específicos, que ameaçavam a organização das cidades e eram diferentes em seus comportamentos e valores de referência.

A diferenciação entre "nós" e "eles" obedece a um sistema classificatório, que divide o mundo social e aponta para quais grupos possuem maior prestígio (Warde, 2011). Estes privilégios, baseados em visões etnocêntricas, oportunizam aos grupos dominantes a afirmação de que os valores, comportamentos e costumes diferentes dos seus são inferiores (Lima, 2011). A realidade migratória contemporânea pode ser tomada como uma conjuntura que permite a visualização desta oposição (Phinney, 2004), uma vez que evidencia e favorece a valorização e demarcação dos grupos pertencentes à sociedade dos países receptores frente aos grupos de imigrantes (Schwartz, Unger, Zamboanga \& Szapocznik, 2010). Freitas e Dantas (2011) argumentam que o estrangeiro, o de fora, causa uma sensação de invasão, na qual o medo do outro aparece em forma de exclusão do imigrante. 
Kozakai e Wolter (2007) citam o exemplo da França, como país que possui grande número de imigrantes e que se apresenta imerso em um movimento de transformação de sua identidade cultural em função da presença do outro. A ameaça cultural que isto representa sugere a formação de uma fechadura identitária que exclui o imigrante e o força a assimilar a cultura nacional de destino com o passar das gerações (Kozakai \& Wolter, 2007). Esta assimilação cultural aponta para uma lógica de inclusão que negligencia o processo de integração dos imigrantes e enfraquece movimentos e construções de relações sociais que respeitem as diferentes inserções culturais de origem (Sawaia, 2007).

A globalização fez com que as fronteiras nacionais e identitárias se fundissem e ameaçassem aqueles que recebem, em maiores quantidades, os imigrantes (Rodrigues, 2012). Além da questão identitária, Lima (2011) argumenta que existem lógicas políticas que influenciam no trato com a diferença, nas quais determinados grupos sociais são utilizados para que se mantenha o status e a hierarquia sociais vigentes. A manutenção do status social implica na necessidade em se ter um grupo ao qual possam ser atribuídas características que são desfavoráveis à sociedade, justificando e sustentando uma composição social desigual (Boneti, 2006; Oliveira, 2012; Woortmann, 2000).

A discussão a respeito das ideias que circulam na sociedade contribuindo para a manutenção da hierarquia social, em função da lógica "dominantes $\mathrm{x}$ dominados", pode ser favorecida pelo aporte teórico-conceitual da Teoria das Representações Sociais (Moscovici, 2003).

\section{Teoria das Representações Sociais}

A Teoria das Representações Sociais constitui uma das possíveis estratégias de acesso à compreensão de como os grupos criam e negociam sentidos sobre os mais diversos objetos sociais e os fenômenos à sua volta (Vasconcelos, Viana \& Santos, 2007). Ao atribuir sentido aos mais diversos objetos, as representações sociais norteiam comportamentos e visam tornar familiar o não familiar, de modo que o desconhecido seja assimilado e incorporado às construções sociais (Moscovici, 2003).

Staerklé (2013) considera que existe uma dualidade de representações de categorias sociais e de grupos. Esta dualidade, denominada pelo autor de antagonismo intergrupal, faz referência ao modo de ratificar determinadas práticas de grupos hegemônicos pautadas em representações sociais dominantes. Há neste ínterim, uma valorização de regras e comportamentos disseminados de acordo com o modelo de desejabilidade social (Staerklé, 2013). 
Em função das práticas hegemônicas, o imigrante, considerado como minoria étnica e social, pode estar vinculado a representações sociais de cunho negativo, que possivelmente contribuem para a emergência de práticas xenófobas e de exclusão (Moscovici, 2011). Dessa forma, é relevante pensar que, apesar da principal função das representações sociais ser a de tornar familiar os novos objetos sociais que entram em circulação no sistema de comunicação dos grupos sociais (Moscovici, 2003), a associação dos imigrantes a categorias inferiores e indesejadas socialmente pode fundamentar a rejeição do diferente e mantê-lo na condição de não familiaridade (Kalampalikis, 2012).

Sobre esse processo de elaboração de categorias sociais que sustentam dinâmicas de negação da alteridade entre grupos sociais em universos conflitivos, como analisado por Cabecinhas (2004), os estereótipos sociais constituem-se como importante dimensão do trabalho social e cognitivo de produção de significados, orientado, principalmente, à formulação de representações sobre grupos humanos. Nessa mesma perspectiva, de acordo com Mendonça e Lima (2014), "tanto as representações sociais quanto os estereótipos referem-se ao saber elaborado pelos indivíduos, e em ambos os casos, as cognições permeiam a compreensão e avaliação, participando da construção da identidade das pessoas" ( $p .193$ ); ou seja, se formam no campo comum dos julgamentos sociais, concorrem à formação da realidade social e psicológica, e são produzidas e propagadas no contexto das relações intergrupais (Mendonça \& Lima, 2014).

Moscovici (2003), ao propor a grande teoria, apresenta conceitos a respeito da gênese das representações sociais que favorecem o entendimento de sua construção. O conceito de objetivação, por exemplo, exprime o fato de uma representação social tornar-se icônica (Pereira \& Camino, 2003), enquanto a ancoragem é compreendida a partir da associação que determinados objetos sociais possuem a categorias, conhecimentos e valores específicos (Deschamps \& Moliner, 2009; Moscovici, 2003).

De maneira dialética à objetivação, a ancoragem articula três etapas básicas das representações sociais, a saber: 1) a função de imprimir significado aos objetos sociais, 2) a função de interpretação destes objetos com base em estruturas e categorias já presentes na sociedade, e 3) a função de orientação de práticas sociais (AlvesMazzotti, 2008). Deste modo, a ancoragem pode ser entendida como processo que orienta e imprime funcionalidade às representações sociais, possibilitando a classificação e hierarquização do novo com base no que já é conhecido (Ordaz \& Vala, 1997). A comunicação midiática possui influência também na maneira pela qual as representações sociais serão propagadas, de modo que podem, até mesmo, fundamentar e alimentar relações sociais conflituosas (Doise, 2011; Moscovici, 2003; Ordaz \& Vala, 1997). 


\section{Representações sociais e mídia}

A existência de narrativas jornalísticas que contribuem para o fortalecimento do medo e para a estigmatização do outro, caracteriza um processo de negativação de certas categorias humanas que se tornam degeneradas na percepção da sociedade (Baggio, 2013; Beneduzi, 2009). Por essa razão, pode-se considerar que as notícias de jornal, majoritariamente, são compostas de matérias referentes aos grupos minoritários que enfatizam a hierarquia social e 0 privilégio dos grupos dominantes (Conti, Bertolini \& Peres, 2010). As notícias de jornal, ao influenciaram as índoles social, ideológica e cultural, representam um processo que determina e enfatiza critérios de inclusão e exclusão de grupos e categorias sociais (Sousa, 2006).

Com relação à imprensa europeia, Santos (2007) afirma que em Portugal, por exemplo, a imagem jornalística que se transmite a respeito da mulher brasileira imigrante, apoia-se em um contexto que enfatiza a prostituição e a ilegalidade. Analisando também a imprensa jornalística em Portugal, Ribeiro (2008) argumenta que as representações sociais vinculadas aos imigrantes naquele território, de maneira estereotipada e discriminatória, oferecem elementos para a discussão e avaliação de características que indicam o não pertencimento às sociedades de destino. Cava (2016), por sua vez, enfatiza que a imprensa italiana reduz a imagem do imigrante à criminalidade, sofrimento, desespero e pobreza, distorcendo a realidade e especulando, através de representações negativas, que os problemas sociais vinculam-se a este grupo social. No Canadá, Esses, Medianu e Lawson (2013) analisam que a mídia tem se proposto a divulgar imagens que sugerem a ligação dos imigrantes com epidemias de doenças e terrorismo, incluindo-os em um contexto de desumanização. Já Cohen e Muhamad-Brandener (2012) afirmam que a imprensa alemã têm se ocupado em repercutir um discurso hegemônico contra culturas não ocidentais, especialmente islâmicas, que afirmam o preconceito e a negação de tudo o que não se encaixa no padrão germânico.

Estas categorias e conteúdos estruturados em oposições (incluído/excluído, positivo/negativo, bom/mau, nós/eles, eu/outro) são gerados a partir de um campo de antinomias culturalmente compartilhado (Marková, 2006). As antinomias possuem regularidade histórica e social, e permitem a constituição e organização de themas, os quais dão origem às representações sociais (Marková, 2006; Moscovici, 2003, 2012). Elas são relevantes para a compreensão da lógica hierárquica que se institui socialmente e possui impacto na relação entre grupos hegemônicos e minoritários (Moscovici, 2011).

A reflexão a respeito dos grupos minoritários, e sua relação com a sociedade hegemônica, recruta o entendimento dos themas em função das antinomias. A existência de um grupo considerado invasor, 
primitivo e desprovido de civilidade, em contraste com a sociedade civilizada e dominante, desde tempos históricos, é considerada providencial para que o 'outro' seja desumanizado e classificado de maneira negativa, marginal e excludente (Pérez, Moscovici \& Chulvi, 2002).

Com base nas proposições apresentadas, o presente estudo teve como objetivo analisar as representações sociais de imigração e de imigrantes difundidas por jornais de referência em três países europeus que possuem grande concentração de brasileiros (Ministério das Relações Exterirores, 2011), a saber: Reino Unido (180.000 brasileiros), Alemanha (91.087 brasileiros) e França (80.010 brasileiros). Apesar de os três países serem pertencentes a um mesmo bloco econômico, cada um deles reflete uma realidade específica de seus territórios nacionais.

No Reino Unido, por exemplo, Dias (2013) salienta que, devido à globalização e às maiores incidências de ocorrência do terrorismo, a questão da integração dos imigrantes é considerada pauta importante ao se discutir a defesa nacional do país. Na Alemanha, Silva, Brites, Oliveira e Borri (2014) pontuam que, ainda hoje, existem partidos de extrema direita que possuem visões conservadoras e fortalecedoras da intolerância aos imigrantes. Já na França, Fassin (2014) argumenta que o país, tendo em vista seu histórico de ajuda a refugiados e de defensor de causas humanitárias e de direitos humanos, encontra-se em um lugar de contradição ao evidenciar, na última década, um tratamento considerado mais repressivo no que se refere às questões ligadas à civilidade dos imigrantes ilegais.

\section{Método}

Baseando-se nas proposições apresentadas, realizou-se uma pesquisa documental a partir de reportagens de jornais dos três países selecionados, a fim de apreender as representações sociais sobre imigração e imigrantes para a sociedade europeia.

\section{Fonte de dados e procedimentos de coleta de dados}

Para cada um dos países, escolheu-se um jornal de grande circulação com base nos critérios de sua popularidade, disponibilidade e gratuidade no acesso online. Os dados foram coletados a partir da utilização da ferramenta de busca online nos sites dos seguintes jornais: No Reino Unido, The Sun; na França, Le Figaro e na Alemanha, Süddeutsche Zeitung. Na busca online, foram inseridas as palavras que favoreciam a apreensão do objeto, observando a tradução das mesmas para as línguas de cada país: imigração, imigrações, imigrante, imigrantes, imigrado, imigrada, imigrados, 
imigradas, imigrar, extracomunitários, extracomunitário, extracomunitária, extracomunitárias, estrangeiro, estrangeira, estrangeiros e estrangeiras.

Como critério para seleção das reportagens, observou-se aquelas que enfatizavam a imigração e os imigrantes apenas em território europeu. Os bancos de dados foram criados com base na busca das reportagens nos dias pares (compreendendo o período de 02 de julho de 2012 a 30 de novembro de 2012). No total, 127 reportagens foram analisadas, sendo 45 do jornal inglês The Sun, 41 do jornal francês Le Figaro e 41 do jornal alemão Süddeutsche Zeitung.

\section{Tratamento dos dados}

Para o tratamento dos dados foi utilizado o recurso da Classificação Hierárquica Descendente (CHD) do software Alceste (IMAGE, 2010). Este software baseia-se em cálculos de co-ocorrência de palavras, em função dos seguimentos textuais, e estrutura classes que representem as diferentes formas de discurso a respeito do objeto de interesse (Nascimento \& Menandro, 2006).

A preparação do corpus de dados analisado pelo software foi realizada a partir do critério para inclusão das reportagens, conforme termos de busca previamente definidos e associados ao tema da migração. A partir da seleção das reportagens, dois juízes independentes procediam a leitura do material recordando o conteúdo textual referente apenas a situações ocorridas no continente europeu. Ressalta-se que, a partir da limpeza das reportagens com base nos contextos migratórios ocorridos na Europa, o material foi analisado na íntegra pelo software Alceste.

\section{Resultados e Discussão}

\section{A autoridade britânica: a representação social de imigração e de imigrantes no jornal The Sun}

O banco de dados referente ao jornal britânico "The Sun" teve $76.53 \%$ de seu corpus analisado e apresentou, a partir da CHD, dendrograma com cinco classes estáveis (Ver Figura 1). As classes se organizam a partir de dois eixos principais: "Ilegalidade e discriminação", constituído pela classe 1 ("Ilegalidade e discriminação"), e "O imigrante ideal", formado pelas classes 2 ("Nós e eles / o discurso do leitor"), 4 ("As regras do Estado"), 5 ("A soberania do Reino Unido") e 3 ("Situações problema"). 


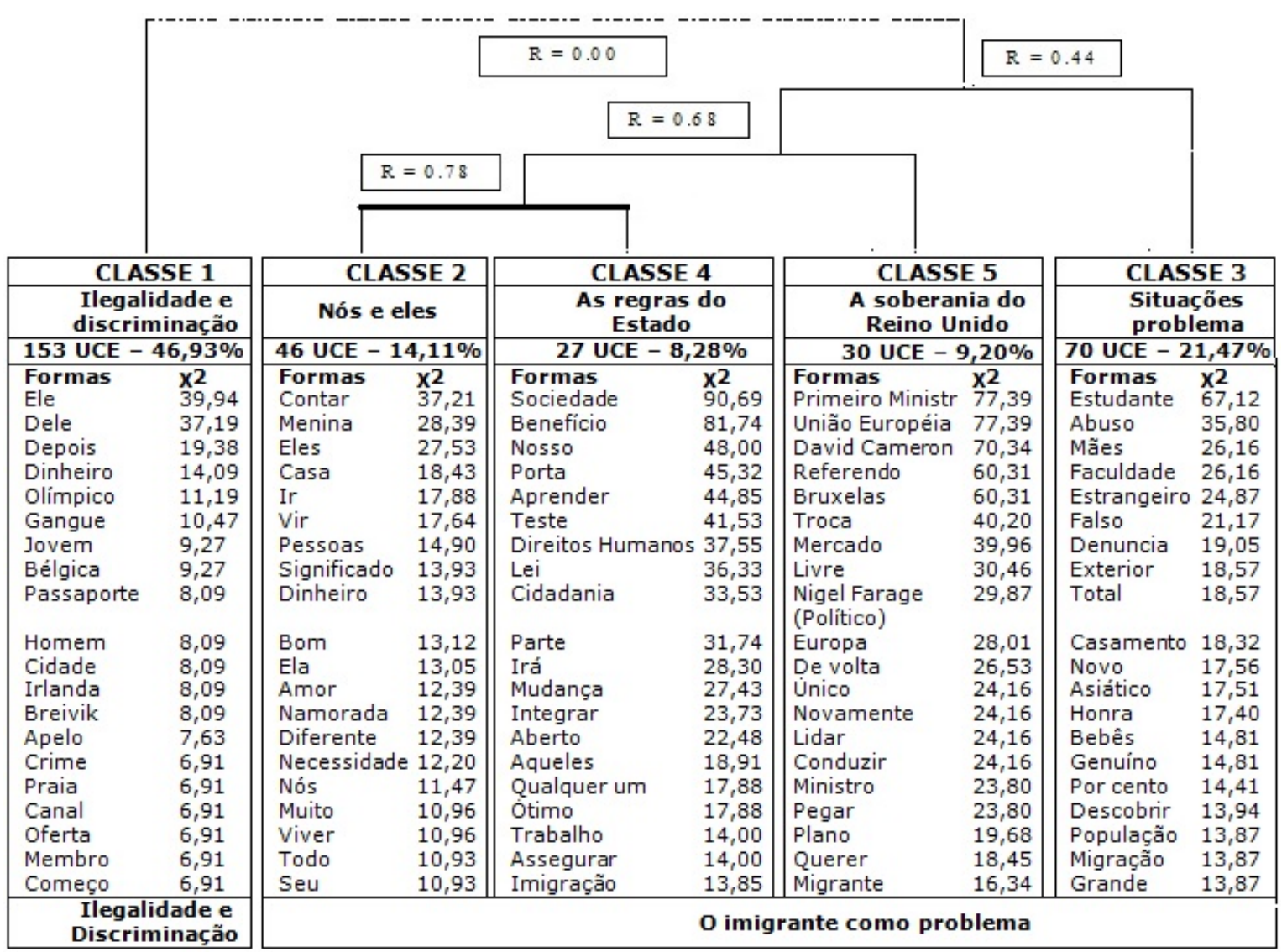

Figura 1. Classificação Descendente Hierárquica do corpus J ornal Britânico “The Sun" - Dendrograma das classes estáveis

O primeiro eixo, composto apenas pela classe 1, abrangeu $46.93 \%$ do total do corpus analisado. Já no segundo eixo, "O imigrante ideal", a classe 2 ( $14.11 \%$ do total do corpus) e a classe 4 (8.28\%) possuem um índice de relação de 0.78 . Relacionada a estas duas classes, por um índice de 0.68 , encontra-se a classe $5(9.20 \%)$, que, integrando esse subconjunto, se liga à classe $3(21.47 \%)$ com força relativa de 0.44 .

\section{I legalidade e discriminação}

O primeiro eixo, formado pela análise das reportagens do jornal inglês, apresenta predominância de elementos que enfatizam a separação entre o britânico e os outros povos que residem não apenas no Reino Unido, mas na Europa em geral. A classe 1, denominada "ilegalidade e discriminação", apresenta palavras como dinheiro, jovem, passaporte e crime, que apontam para um contexto em que a entrada do imigrante no território é dada como fraudulenta e ausente de documentação legal. Em particular, os elementos praia e canal referem-se à recorrente tentativa de entrada de ilegais no país, pelo Canal da Mancha, a nado. 
Imigrante morre \#em cruzamento de \#canal - O \#corpo de uma mulher \#refugiada, usando um traje de mergulho, que tentou \#nadar \#pelo \#canal britânico foi \#encontrado \#em \#praia \#no norte da \#França. ( $\left.x^{2}: 19\right)$.

Este primeiro eixo sinaliza também a preocupação com episódios de discriminação por parte de neonazistas na Europa. A morte por ações discriminatórias e um episódio específico de assassinato de imigrantes (ocorrido na Irlanda) é retratado por elementos como: Breivik (homem neonazista que provocou uma chacina de imigrantes na Noruega), gangue e apelo.

\#Breivik \#escreveu uma \#carta de \#três páginas para \#Zschaepe (criminosa neonazista) esbanjando admiração pelo NSU (grupo alemão terrorista de extrema direita). O norueguês afirma ser fascinado pela \#mulher apelidada de 'lagoa nazista' \#na \#Alemanha. $\left(x^{2}: 17\right)$.

\section{O imigrante ideal}

O eixo "o imigrante ideal" é composto pelas classes 2, 3, 4 e 5. Estas classes demonstram a possibilidade do Estado de conferir cidadania ao imigrante, mediante o cumprimento de determinadas condições, que são acentuadas e demarcam a diferença.

A classe 2, "nós e eles / o discurso do leitor", constitui-se de elementos como eles, pessoas, bom e nós, que evidenciam o "nós" britânicos e o "eles" não-britânicos. Esta classe possui maior proximidade à classe 4, "as regras do Estado", que ressalta as políticas e leis que precisam ser seguidas para que o não-britânico se integre à sociedade. Termos como sociedade, benefício, nosso e aprender indicam esta relação em função da existência de cursos oferecidos pelo Governo Britânico para que o imigrante "aprenda" as leis e a cultura do país.

O guia \#também ressalta que os imigrantes \#devem respeitar \#nossas leis de \#direitos. ( $\left.x^{2}: 22\right)$.

Os elementos presentes nas Classes 1 e 2, além de afirmarem a demarcação das diferenças entre a sociedade britânica e o grupo migrante (Brown \& Zagefka, 2011), permitem a visualização de um contexto no qual se destacam a ilegalidade e a violência decorrentes da pertença a um grupo minoritário (Moscovici, 2011). Na classe 2, pode-se perceber um indicativo do que Kosakai e Wolter (2007) chamam de fechadura identitária, identificada no momento em que os jornais destacam o aprendizado como condição necessária para o que o sujeito migrante tenha direitos reconhecidos. A imagem de 
imigrante 'ideal' expressa nestas condições permite a organização de uma imagem de desejabilidade social (Staerklé, 2013), na qual o grupo deve distanciar-se das problemáticas que a sociedade receptora enfrenta e adequar-se a ela.

Ao se discutir a articulação feita pelo conceito de ancoragem (AlvesMazzotti, 2008; Deschamps \& Moliner, 2009; Moscovici, 2003; Ordaz \& Vala, 1997), pode-se compreender que estas representações sociais organizam um campo de significados que vinculam 0 imigrante à condição de estranho à sociedade, que necessita de ajustamento. Dessa forma, a imagem associada à imigração e ao imigrante pode suscitar o enfraquecimento das relações entre os grupos (Sawaia, 2007) e orientar práticas de exclusão (Moscovici, 2011; Ribeiro, 2008).

Mais próxima às classes 2 e 4 , a classe 5 "a soberania do Reino Unido" possui em sua formação palavras que ratificam a imponência do Estado Britânico. Elementos como primeiro ministro, união europeia e referendo indicam a questão de um momento atual do país que considera um referendo acerca da possibilidade de se separar da União Europeia devido à crise econômica na Europa. O Estado Britânico mostra-se, nesta classe, preocupado com o imigrante que vem do próprio continente europeu, uma vez que este tem passe livre pelos países do bloco.

O povo britânico merece uma verdadeira escolha em um \#referendo direto sobre a entrada ou \#saída. ( $\left.x^{2}: 46\right)$.

Assim como afirma Dias (2013), o Reino Unido evidencia uma preocupação com a defesa de sua territorialidade em função das migrações. A saída do país da União Europeia pode ser justificada como uma forma de proteção nacional na qual se presume um medo da invasão de imigrantes (Freitas \& Dantas, 2011).

Distante das demais classes (com um índice de ligação de 0.03), a classe 3 "situações problemas" descreve uma série de acontecimentos (como alta taxa de natalidade das estrangeiras em comparação às britânicas e denúncias de estudantes estrangeiros com documentação falsa em faculdades do Reino Unido), que colocam o indivíduo imigrante em uma condição de envolvimento em transtornos e perturbações à ordem do país. Alguns elementos como abuso, falso, denuncia, mães e bebês ilustram estas situações. A vinculação da imigração a situações que demonstram problemas sociais pode justificar a intenção do país em demarcar suas fronteiras (Dias, 2013; Schwartz, Unger, Zamboanga \& Szapocznik, 2010).

De modo geral, apesar de o jornal britânico "The Sun" apresentar as circunstâncias nas quais o Estado considera plausível a presença imigratória, em função do 'imigrante ideal', este enfatiza significados que demonstram uma conjuntura na qual o país demarca sua 
soberania nacional e a hierarquia presente entre os britânicos e os não britânicos (Conti, Bertolini \& Peres, 2010).

O imigrante cidadão: a representação social de imigração e de imigrantes no jornal Le Fígaro

A análise do banco de dados do jornal francês "Le Figaro" teve um aproveitamento de $77.19 \%$ do material coletado. A CHD do software Alceste apresentou um dendrograma (Ver Figura 2) de quatro classes, que se separam em dois eixos temáticos.

As classes 1 ("Violência contra o imigrante", com $18.23 \%$ do corpus analisado), 2 ("Ilegalidade e discriminação", com 13.29\% do corpus) e 3 ("Imigração ilegal pelo mar", $16.75 \%$ do corpus) formam o primeiro eixo de análise denominado "Criminalização e exclusão". As classes 1 e 2 relacionam-se com um índice de 0.68 e, ligada a elas, está a classe $3(R=0.52)$. O segundo eixo de análise é formado apenas pela classe 4 ("Eleições") e representa $51.23 \%$ do corpus analisado. 


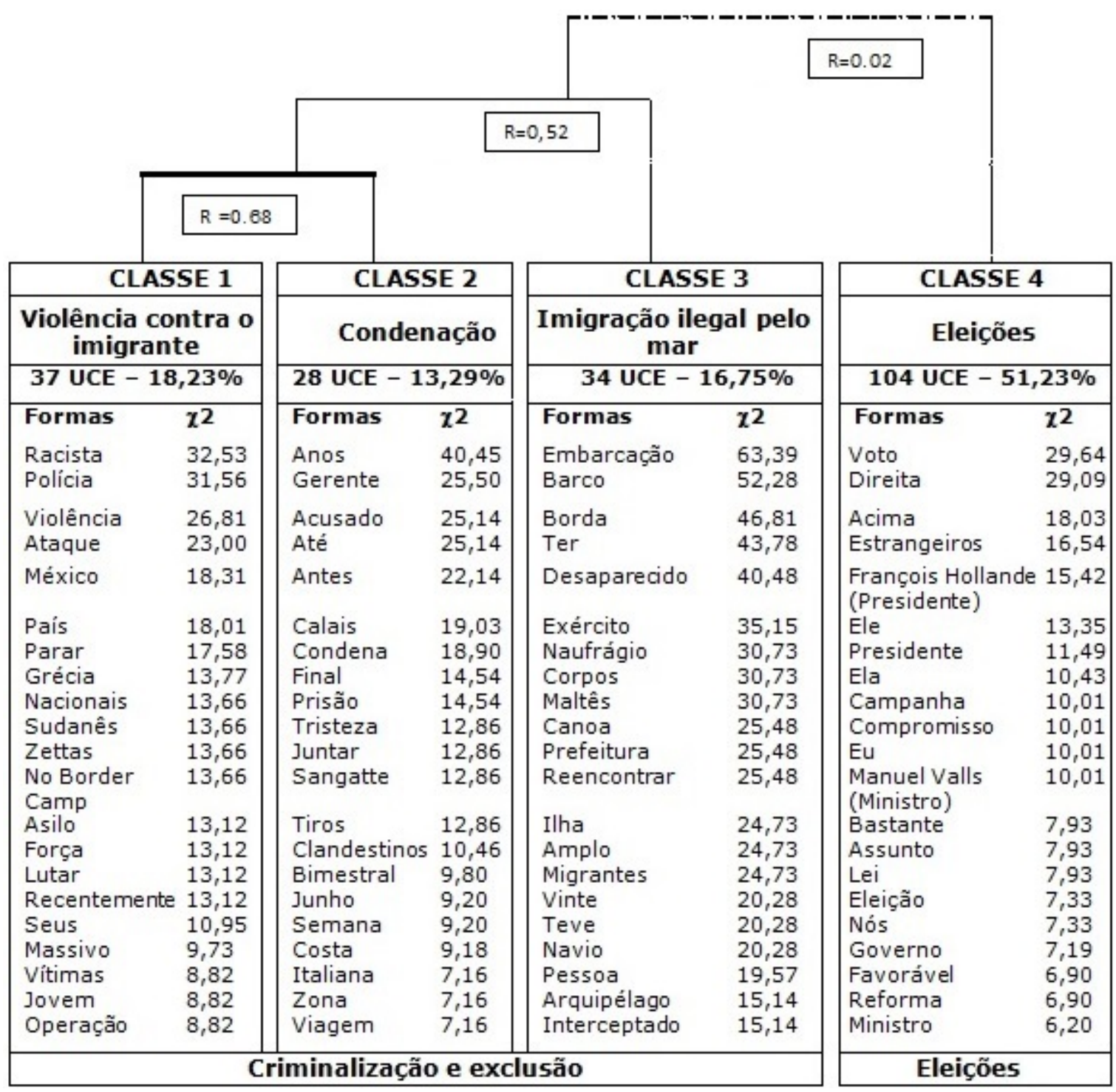

Figura 2. Classificação Descendente Hierárquica do corpus Jornal Francês "Le Figaro" - Dendrograma das classes estáveis

\section{Criminalização e exclusão}

O primeiro eixo denominado "criminalização e exclusão" apresenta um cenário de descrição e crítica à violência e ilegalidade. A classe 1 , "violência contra o imigrante", aponta para um panorama de ações discriminatórias, indicadas em termos como racista, polícia, violência e ataque, que são analisadas pelo jornal como intransigentes e como dimensões a serem combatidas. Apesar do jornal britânico também destacar a imagem de violência associada ao grupo imigrante, no jornal francês percebe-se maior ênfase.

Foram denunciadas, \#recentemente, repressões \#maciças \#contra os \#ilegais. $\left(x^{2}: 25\right)$. 
A análise destes elementos no jornal francês pode indicar que as representações sociais em questão ancoram-se em estruturas e categorias presentes no pensamento social do país que se vinculam ao seu histórico de associações à luta pelos direitos humanos, como discute Fassin (2014). Os significados que circulam na sociedade a respeito dos grupos minoritários são constituídos em função da luta histórica francesa pelas causas humanitárias, o que sinaliza que a conduta social em relação ao imigrante é orientada de maneira contraditória devido à forte repreensão à imigração ilegal (Fassin, 2014; Ordaz \& Vala, 1997).

A classe 2 "ilegalidade e discriminação" indica crimes cometidos contra imigrantes e a condenação de seus responsáveis. No entanto, nesta classe é possível reconhecer a referência à ilegalidade, na qual se destaca a entrada clandestina na Europa pela costa marítima, assim como evidenciada no jornal The Sun, pelos elementos acusado, condena, prisão e clandestina. Já na classe 3, “imigração ilegal pelo mar", há referência, majoritariamente, à entrada no continente europeu pela costa marítima. A classe sobre "imigração ilegal pelo mar" é representada por elementos que enfatizam os naufrágios, desaparecidos e mortos (corpos).

\#Mortos \#durante \#um \#naufrágio de \#migrantes - \#Vinte \#imigrantes \#clandestinos \#pereceram \#hoje \#durante um \#naufrágio de \#uma \#embarcação, \#à altura da costa oeste da Turquia. ( $\left.x^{2}: 42\right)$.

\section{Eleições}

O segundo eixo de análise do jornal francês compreende apenas a classe 4 "eleições". Esta classe representa a maior parte do conteúdo analisado e alude a uma discussão feita durante o período em que foi realizada a coleta de dados neste jornal. As eleições municipais são o tema principal da classe e apresentam a discussão do direito de voto pelos imigrantes residentes na França. Termos como voto, campanha, lei e eleição elucidam o conteúdo e indicam uma discussão mais crítica com relação à participação do imigrante na determinação da estrutura da sociedade francesa.

\#A respeito do \#direito de \#voto, as pessoas estão mudando certos \#pontos de vista. Alguns estão menos contra do que \#antes. ( $\left.x^{2}: 19\right)$.

No jornal francês, de maneira geral, à imigração e ao imigrante são relacionadas imagens que os consideram como importantes na discussão da constituição populacional do país. Porém, embora haja o reconhecimento dos direitos civis dos que lá residem, as reportagens 
evidenciam a questão da ilegalidade em associação à criminalidade e à desordem social (Lima, 2011; Oliveira, 2012). A violência sofrida e a questão da clandestinidade por meio das embarcações, bem como suas consequências, simbolizam que, apesar da discussão em favor da inclusão do imigrante, este é ainda significado como o "de fora" e portador de ameaças (Baggio, 2013; Beneduzi, 2009, Esses, Medianu \& Lawson, 2013).

\section{Pobreza e violência: a representação social de imigração e de imigrantes no jornal Süddeutsche Zeitung}

O jornal alemão "Süddeutsche Zeitung" mostrou-se crítico em relação à violência sofrida pelos imigrantes na Alemanha. Conforme pode ser observado na Figura 3, $82.60 \%$ de seu corpus foi analisado, originando 3 classes. A primeira classe (Violência contra o imigrante) compõe o primeiro eixo de análise e representa a maior parte do banco $(51.47 \%)$. Já o segundo eixo é composto pelas classes 2 (Pobreza e exclusão) e 3 (Refugiados), que se relacionam com um índice de 0.52 .

\begin{tabular}{|c|c|c|c|c|c|}
\hline & & $\mathrm{R}=0,00$ & & $R=0.51$ & \\
\hline \multicolumn{2}{|l|}{ CLASSE 1} & \multicolumn{2}{|c|}{ CLASSE 2} & \multicolumn{2}{|c|}{ CLASSE 3} \\
\hline \multirow{2}{*}{\multicolumn{2}{|c|}{$\frac{\text { Violência contra o imigrante }}{193 \text { UCE }-51,47 \%}$}} & \multirow{2}{*}{\multicolumn{2}{|c|}{$\begin{array}{c}\text { Pobreza e Exclusão } \\
146 \text { UCE - 38,93\% }\end{array}$}} & \multicolumn{2}{|c|}{ Refugiados } \\
\hline & & & & \multicolumn{2}{|c|}{36 UCE - 9,60\% } \\
\hline Formas & $x^{2}$ & \multicolumn{2}{|c|}{ Formas } & Formas & $x^{2}$ \\
\hline Neonazistas & 25,26 & Eles & 25,22 & Requerente de asilo & 79,79 \\
\hline Grupo & 10,69 & Mais & 19,77 & Viemos & 66,80 \\
\hline NSU* & 10,69 & Poder*** & 19,44 & Doze & 47,72 \\
\hline Vítima & 9,69 & Seu & 19,11 & Dever**** & 38,20 \\
\hline Constituição Administrativa & 9,69 & Crianças & 18,08 & Instituição Federal & 38,20 \\
\hline Polícia & 8,69 & Quase & 11,19 & Síria & 38,07 \\
\hline Contra & 8,59 & Pobreza & 11,19 & Bad Tolz**** & 30,38 \\
\hline Ministério do Interior & 8,02 & Lá & 11,08 & Refugiados & 30,38 \\
\hline Foram & 8,02 & Sem & 11,08 & Apesar de & 28,94 \\
\hline Livro & 7,71 & Quando & 10,45 & Três & 28,94 \\
\hline Arquivos & 7,71 & Tempo & 10,17 & Atualmente & 28,94 \\
\hline Assassinato & 7,71 & Itália & 9,68 & Proibição de trabalho & 28,48 \\
\hline Repartição de Segurança & 6,73 & Lar & 9,68 & Mês & 26,38 \\
\hline Afiliação & 6,73 & Problema & 9,56 & Primeiro & 24,74 \\
\hline Quem & 6,73 & Cinco & 9,56 & Migração & 22,88 \\
\hline Nós & 6,73 & Dinheiro & 9,56 & No mínino & 19,93 \\
\hline Twitter** & 6,73 & Seus & 9,56 & Estes & 19,93 \\
\hline Cidade & 6,11 & Por cento & 8,77 & Aqueles & 15,37 \\
\hline Ação & 6,11 & Euro & 8,77 & Bavária & 15,37 \\
\hline Ativistas & 5,75 & Munique $* * *$ & & Oferecer & 15,37 \\
\hline \multicolumn{2}{|c|}{ Violência Neonazista } & \multicolumn{4}{|c|}{ Pobreza } \\
\hline
\end{tabular}

Nota: NSU* (Nationalsozialistischer Untergrund = Grupo terrorista alemão de extrema direita); Twitter** - Referencia à rede social virtual. Poder/ Dever*** Referencia aos verbos; Munique/Bad Tolz**** - Cidades na Alemanha.

Figura 3. Classificação Descendente Hierárquica do corpus Jornal Alemão "Süddeutsche Zeitung" - Dendrograma das classes estáveis 


\section{Violência neonazista}

A classe 1 "violência contra o imigrante" refere-se à violência sofrida pelos imigrantes, praticada por parte dos grupos neonazistas no país. Possui elementos como neonazistas, polícia, assassinato e ativistas, demonstrando a preocupação com a incidência da violência xenófoba que persiste na Alemanha nos dias atuais (Silva, Brites, Oliveira \& Borri, 2014).

\#Munique foi o palco principal \#de duas \#das \#dez \#mortes cometidas \#pelo grupo terrorista de extrema direita \#NSU \#Clandestinidade Nacional-Socialista. ( $\left.x^{2}: 17\right)$.

\section{Pobreza}

A classe 2 "pobreza e exclusão" retrata a situação de miserabilidade que os imigrantes que chegam à Alemanha se encontram, sendo caracterizada, principalmente, pelos refugiados. Elementos como pobreza, problema e dinheiro fazem parte desta classe que representa o momento econômico de crise e as preocupações com os grupos estrangeiros que devem ser integrados à população.

Os \#pobres na \#Alemanha são, geralmente, \#pobres de \#fora - A \#pobreza na \#Alemanha tem muitas \#faces: \#alguns são trabalhadores qualificados, mas existem \#mães solteiras que se questionam onde \#encontrarão \#comida e também \#roupas. $\left(x^{2}: 29\right)$.

Em consonância, a classe 3 "refugiados", enfatiza elementos como requerentes de asilo e proibição de trabalho. Juntas estas classes formam o eixo "pobreza", conforme UCE: "Trabalho para requerente de \#asilo \#deve passar de \#doze para \#nove \#meses \#apenas" ( $x^{2}$ : 36).

As representações sociais sobre a imigração e sobre o imigrante no jornal "Süddeutsche Zeitung" congregam significados que consideram o grupo como problema marginal à sociedade alemã, em função não só dos imigrantes, mas, também dos refugiados. A delimitação das mazelas sofridas por migrantes e refugiados indicada nas reportagens demarca uma imagem que categoriza esta população em grupos inferiores e desfavoráveis à imagem social (Boneti, 2006). Os significados que associam o imigrante à categoria de pobreza e exclusão contribuem para que o grupo seja classificado como diferente da sociedade local e para que esta continue a possuir maior privilégio (Cava, 2016; Lima, 2011; Warde, 2011).

Desse modo, considerando que a principal tarefa das representações sociais é a de transformar o não familiar em familiar (Vasconcelos, 
Viana \& Santos, 2007), entende-se que os significados associados aos imigrantes nos três jornais analisados são ancorados em estruturas que ilustram categorias inferiores da sociedade, a partir da atribuição de características negativas e desfavoráveis ao grupo (Boneti, 2006; Cohen \& Muhamad-Brandner, 2012; Oliveira, 2012; Woortmann, 2000).

A violência de extrema direita, por sua vez, aparece como ponto importante a ser combatido pelas autoridades do Estado e demonstram uma imagem do imigrante como vítima, bem como o desejo de exclusão deste grupo por parte dos partidos nacionalistas. Contudo, apesar da existência destes eventos violentos nas notícias, há que se refletir que a crítica e preocupação com a permanência do movimento neo-nazista (Silva, Brites, Oliveira, \& Borri, 2014) pode ser um ponto importante para que seja possível a ressignificação das representações sociais que anteriormente, na história do país, prestavam-se à orientação apenas de condutas de aniquilação do estranho e diferente.

\section{Análise integrada}

A análise de cada um dos jornais europeus apresenta especificidades e contextos situacionais referentes à realidade e ao momento da coleta dos dados. No jornal "The Sun", a ênfase à hegemonia do Reino Unido perante a integração dos imigrantes, demonstra que este território demarca suas fronteiras nacionais e sociais, expondo as diferenças e as regras do Estado. O cenário de violência também é destacado nas pautas do jornal, apresentando que, naquele lugar, a legitimação da violência contra o diferente é um tema relevante.

No "Le Figaro", na França, apesar de ser possível uma análise de conjuntura específica das eleições, nota-se que a principal discussão refere-se à inclusão/exclusão do migrante no grupo nacional francês, que possui direitos civis. Além disso, a ilegalidade pelo mar e a violência legitimada, assim como no Reino Unido, apresenta-se como ponto de pauta nas reportagens. Já na Alemanha, o jornal "Süddeutsch Zeitung" identifica o imigrante e a imigração como pertencente à categoria dos refugiados e pobres, que sofrem violência dos conservadores neonazistas.

Tendo em vista a discussão a respeito do conceito de ancoragem da Teoria das Representações Sociais, entende-se que, inicialmente, as representações sociais imprimem significados aos objetos, designando-os uma definição e sentidos próprios (Alves Mazzotti, 2008; Ordaz \& Vala, 1997). Deste modo, embora seja observada a existência de particularidades nacionais em cada um dos jornais, pode-se compreender que, de maneira geral, os significados associados às representações sociais de imigração e imigrante referem-se à ideia de violência, ilegalidade, criminalidade e exclusão. 
Nesta etapa da formação da representação, nota-se que o imigrante é relacionado a categorias desvalorizadas, uma vez que ocupa um lugar de marginalização e exclusão (Oliveira, 2012).

Entendendo que as representações sociais são construídas a partir de themas e categorias já presentes na sociedade (Deschamps \& Moliner, 2009; Marková, 2006; Moscovici, 2003), na discussão a respeito do conceito de ancoragem, compreende-se que os significados atribuídos ao objeto imigração e imigrante podem ser interpretados em função de sua vinculação à ideia da demarcação da oposição e diferença (Brown \& Zagefka, 2011). As antinomias presentes na constituição das sociedades estabelecem uma relação de oposição e dialogicidade que institui lugar de fronteira entre 'europeus' e 'não-europeus', entre 'civilizados' e 'primitivos' e entre 'sociedade' e 'invasores', em função de visões etnocêntricas e hierárquicas de que o 'outro', o diferente, ameaça a estrutura social (Lima, 2011; Marková, 2006).

A classificação entre 'nós' e 'eles' é verificada muito anteriormente à existência do entendimento de civilização que vigora na atualidade. $O$ objeto imigrante é localizado na composição das histórias humanas como o "primitivo" ou "selvagem", assim como descreve Woortman (2000) ao ilustrar a civilização grega nos tempos de Heródoto. A sociedade detentora de privilégios e de maior prestígio criava e classificava a concepção do que seria o "selvagem" para, posteriormente, projetá-la em povos que se apresentavam como diferentes ou como invasores (Warde, 2011; Woortman, 2000).

Constata-se que as representações sociais de imigração e imigrantes possuem significados que se ancoram em themas presentes no pensamento social de maneira histórica e resgata a noção de que o 'de fora' é negativo e causa medo (Baggio, 2013; Beneduzi, 2009). Segundo Pérez, Moscovici e Chulvi (2002), a relação de discriminação e negativização do 'outro' torna-se adequada à função de desumanização e exclusão de grupos minoritários. Em associação à ideia geral de "primitivo" e "invasor", já concebida nas sociedades antigas (Woortman, 2000), as representações sociais de imigração e imigrantes apóiam-se em ambivalências coniventes com a manutenção da ordem social vigente.

O conceito de ancoragem propõe que os significados associados aos objetos orientam determinadas práticas sociais (Alves Mazzotti, 2008; Moscovici, 2003; Ordaz \& Vala, 1997). No que se refere ao objeto imigração e imigrante, observa-se que as representações sociais dos jornais europeus em análise estabelecem uma relação de oposição entre os imigrantes e sociedade local, de modo que a diferença entre estes dois grupos é enfatizada. Em função dos significados de cunho negativo, depreende-se que as representações sociais analisadas podem orientar e legitimar práticas de violência, uma vez que se assume o imigrante como criminoso e ilegal, aquele 
que é 'de fora', desconhecido e que causa sensação de invasão (Dias, 2013; Freitas \& Dantas, 2011).

Considerando que a principal função das representações sociais é a de tornar familiar o não familiar (Moscovici, 2003; Vasconcelos, Viana \& Santos, 2007), entende-se que as representações sociais de imigração e imigrante para os jornais europeus em analise fornecem panorama díspar ao favorecer a permanência do objeto social em questão no campo do desconhecido (Kalampalikis, 2012). A vinculação do objeto aos themas e categorias que possuem caráter inferior no pensamento social, e constituem-se como indesejados, pode estabelecer uma rejeição do diferente e manter o grupo na condição de não familiaridade (Kalampalikis, 2012).

\section{Considerações Finais}

O presente estudo teve como objetivo conhecer e analisar as representações sociais de imigração e imigrantes a partir de reportagens veiculadas em três jornais de grande circulação em três países europeus: Reino Unido, França e Alemanha. Considera-se que o fenômeno migração apresenta-se como favorável à discussão das funções das representações sociais para as relações sociais estabelecidas entre os diferentes grupos nos países de destino.

Os resultados encontrados destacam que os jornais escolhidos para análise possuem suas particularidades, como, por exemplo: no jornal inglês a discussão a respeito da inclusão do imigrante em função do aprendizado de sua cultura nacional; no jornal francês a exposição de um período de debates sobre os direitos do grupo migrante nas eleições; e no jornal alemão, a temática sobre a violência neonazista no país. Contudo, embora existam singularidades, nota-se que todos os países manifestam representações sociais dos imigrantes que categorizam o grupo como inferior perante a hierarquia social estabelecida. A demarcação da diferença entre "nós" e "eles" imprime às representações sociais a função de orientar práticas que não integrem o sujeito imigrante, e que não transforme o diferente em familiar, fortalecendo a manutenção do status social vigente.

Assim como afirmam Ribeiro (2008) e Cava (2016), a impressa jornalística esforça-se para demarcar o não pertencimento dos imigrantes à sociedade europeia a partir da repercussão de estereótipos negativos associados a problemas sociais. 0 distanciamento daquilo que não pertence à sociedade hegemônica é refletido na necessidade midiática de enfatizar as diferenças socioculturais através da distorção da realidade social dos imigrantes (Cava, 2016; Esses, Medianu \& Lawson, 2013; Cohen \& MuhamadBrander, 2012). Analisa-se, contudo, que as representações sociais depreendidas dos jornais em análise podem ser específicas de um 
contexto social e econômico, o que caracteriza uma das limitações do presente trabalho. Por esta razão, é pertinente que outros estudos contemplem outros períodos sociais e, até mesmo, outros países e continentes a fim de se ter uma visão mais transcultural e atualizada do fenômeno.

A fim de propor desenvolvimento de estudos que articulem a Teoria das Representações Sociais e o fenômeno imigração, sugere-se novos trabalhos que enfatizem a investigação de variáveis psicossociais como sistemas de crenças e ideologias para a formulação de estereótipos e preconceitos relacionados à migração no território europeu.

\section{Referências}

Alves-Mazzotti, A. J. (2008). Representações sociais: aspectos teóricos e aplicações à educação. Revista Múltiplas Leituras, 1(1), 18-43.

Baggio, A. T. (2013). A temática homossexual na publicidade de massa para público gay e não-gay: conflito entre representação e estereótipo. Revista Uninter de Comunicação, 1(1), 101-117.

Beneduzi, L. F. (2009). Alguns lugares de memória de processos diaspóricos: narrativas de mulheres brasileiras e argentinas na Itália contemporânea. Tempo e Argumento - Revista do Programa de Pós-Graduação em História da UDESC, 1(2), 0320.

Boneti, L. W. (2006). Exclusão e inclusão social: teoria e método. Revista Contexto e Educação, 21(75), 187-206.

Brown, R., \& Zagefka, H. (2011). The Dynamics of acculturation: an intergroup perspective. Advances in Experimental Social Psychology, 44, 129-184.

Cabecinhas, R. (2004). Processos cognitivos, cultura e estereótipos sociais. Actas do II Congresso Ibérico de Ciências da Comunicação. Universidade da Beira Interior, Covilhã, 21-24.

Cava, A. (2016). Phantoms without a history: immigrants and media in I taly. Journalism and Mass Communication, 6(10), 594-599.

Cohen, B. M. Z., \& Muhamad-Brandner, C. (2012). A school for scandal: Rütli High School and the German press. In G. Morgan, \& S. Poynting (Eds.), Global Islamophobia: Muslims and moral panic in the West (pp. 15-34). London: Routledge.

Conti, M. A., Bertolini, M. N. T. \& Peres, S. V. (2010). A mídia e o corpo: o que o jovem tem a dizer? Ciência \& Saúde Coletiva, 15(4), 2095-2103.

Deschamps. J. C., \& Moliner, P. (2009). A identidade em psicologia social: dos processos identitários às representações sociais. (L. M. E. Orth, Trad.). Petrópolis: Vozes. 
Dias, C. D. O. (2013). Medidas de ação contra o terrorismo: o caso do Reino Unido. Tese de Doutorado. Departamento de Ciências Sociais, Políticas e do Território. Universidade de Aveiro.

Doise, W. (2011). Sistema e metassistema. In A. M. O. Almeida, M. F. S. Santos \& Z. A. Trindade (Orgs.), Teoria das representações sociais 50 anos (pp. 123-156). Brasília: Technopolitik.

Esses, V. M., Medianu, S., \& Lawson, A. S. (2013). Uncertainty, threat, and the role of the media in promoting the dehumanization of immigrants and refugees. Journal of social issues, 63(3), 518-536.

Fassin, D. (2014). Compaixão e repressão: a economia moral das políticas de imigração na França. Ponto Urbe, 15(1), 01-22.

Freitas, M. E., \& Dantas, M. (2011). O estrangeiro e o novo grupo. Revista: RAE - Revista de Administração de Empresas, 51(6), 601-608.

IMAGE. (2010). Alceste 2010 Versão Windows. Software de análises textuais. Targetware Informática LTDA. Disponível em http://www. alcestesoftware. com.br/manuais/alcestemanual.pdf. Acesso em 20 de novembro de 2013.

Kalampalikis, N. (2012). Relato de pesquisa. Das representações sociais: ancoragens, terrenos, tensões. Educação \& Linguagem, 15(25), 245-251.

Kozakai, T., \& Wolter, R. P. (2007). Armadilhas do multiculturalismo: análise psicossocial da integração à francesa dos estrangeiros. Aletheia, 26, 11-26.

Lima, M. E. O. (2011). Da diferença à indiferença: racismo contra índios, negros e ciganos no Brasil. In E. M. Techio, \& M. E. O. Lima (Orgs.), Cultura e produção das diferenças: estereótipos e preconceitos no Brasil, Espanha e Portugal (pp. 217-245). Brasília: Technopolitik.

Marková, I. (2006). Dialogicidade e representações sociais: as dinâmicas da mente. Petrópolis: Vozes.

Mendonça, A. P., \& Lima, M. E. O. (2014). Representações sociais e cognição social. Psicologia e Saber Social, 3(2), 191-206.

Ministério das Relações Exteriores. (2011). Brasileiros no Mundo Estimativas. Recuperado em 21 de agosto de 2013 de http: //sistemas.mre.gov.br/kitweb/datafiles/BRMundo/ptbr/file/Brasileiros\% 20no\% 20Mundo\% 202011\% 20$\% 20$ Estimativas\% 20 -

\% 20Terceira\% 20Edi\% C3\% A7\% C3\% A30\% 20-\% 20v2.pdf

Moscovici, S. (2003). Representações Sociais: investigações em psicologia social. (4a Ed) (P. A. Guareschi, Trad.). Petrópolis, RJ : Editora Vozes.

Moscovici, S. (2011). A Psicologia das minorias ativas. Grupo de leitura "Ideologia, Comunicação e Representações Sociais" (Trads.). Petrópolis: Vozes. 
Moscovici, S. (2012). A Psicanálise, sua imagem e seu público. (S. Fuhrmann, Trad.). Petrópolis, RJ: Editora Vozes. (Obra original publicada em 1961).

Nascimento, A. R. A., \& Menandro, P. R. M. (2006). Análise lexical e análise de conteúdo: uma proposta de utilização conjugada. Estudos e Pesquisas em Psicologia, 6(2), 72-88.

Oliveira, R. S. (2012). Imagens estereotipadas em pauta: o discurso dos jornais surinameses sobre os imigrantes brasileiros (20072010). Espaço \& Geografia, 15(2), 443-474.

Ordaz, O., \& Vala, J. (1997). Objectivação e ancoragem das representações sociais do suicídio na imprensa escrita. Análise Social, 32(143/144), 847-874.

Pereira, C., \& Camino, L. (2003). Representações sociais, envolvimento nos direitos humanos e ideologia política em estudantes universitários de João Pessoa. Psicologia: Reflexão e Crítica, 16(3), 447-460.

Pérez, J. A., Moscovici, S. \& Chulvi, B. (2002). Natura y cultura como principio de clasificación social. Anclaje de representaciones sociales sobre minorías étnicas. Revista de Psicología Social, 17(1), 51-67.

Phinney, J. (2004). Formação da identidade de grupo e mudança entre migrantes e seus filhos. In S. D. DeBiaggi, \& G. J. Paiva (Orgs.), Psicologia e/imigração e cultura. (pp. 47-63). São Paulo: Casa do Psicólogo.

Ribeiro, M. M. (2008). As representações do imigrante brasileiro no jornalismo impresso local: estudo de caso comparado entre o Diário do Minho (Braga - Portugal) e L'Adige (Trento - Itália). Dissertação de Mestrado. Instituto de Ciências Sociais. Universidade do Minho, Portugal. 169f.

Rodrigues, M. A. (2012). Mobilidade precária em terra estrangeira e em estive em Lisboa e lembrei de você. Estudos de literatura brasileira contemporânea, 1(39), 181-192.

Santos, C. A. (2007). Imagens de mulheres imigrantes na imprensa portuguesa. Análise do ano de 2003. Dissertação de Mestrado em Comunicação e Jornalismo. Faculdade de Letras, Universidade de Coimbra, Portugal.

Sawaia, B. B. (2007). Introdução: exclusão ou inclusão perversa? In Artimanhas da exclusão: análise psicossocial e ética da desigualdade social (7a Ed.) (pp. 7-15). Petrópolis: Vozes.

Schwartz, S. J., Unger, J. B., Zamboanga, B. L. \& Szapocznik, J. (2010). Rethinking the concept of acculturation: Implications for theory and research. American Psychologist, 65(4), 237-251.

Silva, A. B., Brites, C. M., Oliveira, E. C. R., \& Borri, G. T. (2014). A extrema-direita na atualidade. Serviço Social \& Sociedade, 1(119), 407-445. 
Sousa, J. P. (2006). Elementos de teoria e pesquisa da comunicação e da mídia. Porto: Editora Letras Contemporâneas.

Staerklé, C. (2013). The true citizen: social order and intergoup antagonisms in political lay thinking. Papers on Social Representations, 22, 1.1-1.21.

Vasconcelos, K. M., Viana, K. M., \& Santos, M. F. S. (2007). Pensando o método de pesquisa em representação social. In M. M. P. Rodrigues, \& P. R. M. Menandro (Orgs.), Lógicas Metodológicas: trajetos de pesquisa em Psicologia (pp. 39-57). Vitória: GM Editora.

Warde, A. (2011). Cultural consumption, classification and power. In A. Warde (Ed.), Cultural consumption, classification and power (pp. 1-3). New York: Routledge.

Woortman, K. (2000). O selvagem e a história. Heródoto e a questão do outro. Revista de Antropologia, 43(1), 13-59.

\section{Endereço para correspondência \\ Roberta Rangel Batista}

Universidade Federal do Espírito Santo - UFES

Programa de Pós-Graduação em Psicologia

Av. Fernando Ferrari, 514, Edifício Lídio de Souza, Goiabeiras, CEP 29075-910, Vitória - ES, Brasil

Endereço eletrônico: roberta.ufes2012@gmail.com

\section{Mariana Bonomo}

Universidade Federal do Espírito Santo - UFES

Programa de Pós-Graduação em Psicologia

Av. Fernando Ferrari, 514, Edifício Lídio de Souza, Goiabeiras, CEP 29075-910, Vitória - ES, Brasil

Endereço eletrônico: marianadalbo@gmail.com

Recebido em: 31/08/2015

Reformulado em: 05/01/2017

Aceito em: 05/01/2017

\section{Notas}

* Graduada e Mestre em Psicologia. Atualmente é aluna de Doutorado no Programa de Pós-Graduação em Psicologia (PPGP) da Universidade Federal do Espírito Santo (UFES). Vitória/ES, Brasil.

** Doutora em Psicologia. Professora do Programa de Pós-Graduação em Psicologia (PPGP) e do Departamento de Psicologia Social e do Desenvolvimento (DPSD) da Universidade Federal do Espírito Santo (UFES). Universidade Federal do Espírito Santo, Vitória, Brasil. 